Document downloaded from:

http://hdl.handle.net/10251/51206

This paper must be cited as:

Alcázar Ortega, M.; Escrivá Escrivá, G.; Segura Heras, I. (2011). Methodology for validating technical tools to assess customer Demand Response: Application to a commercial customer. Energy Conversion and Management. 52(2):1507-1511. doi:10.1016/j.enconman.2010.10.018.

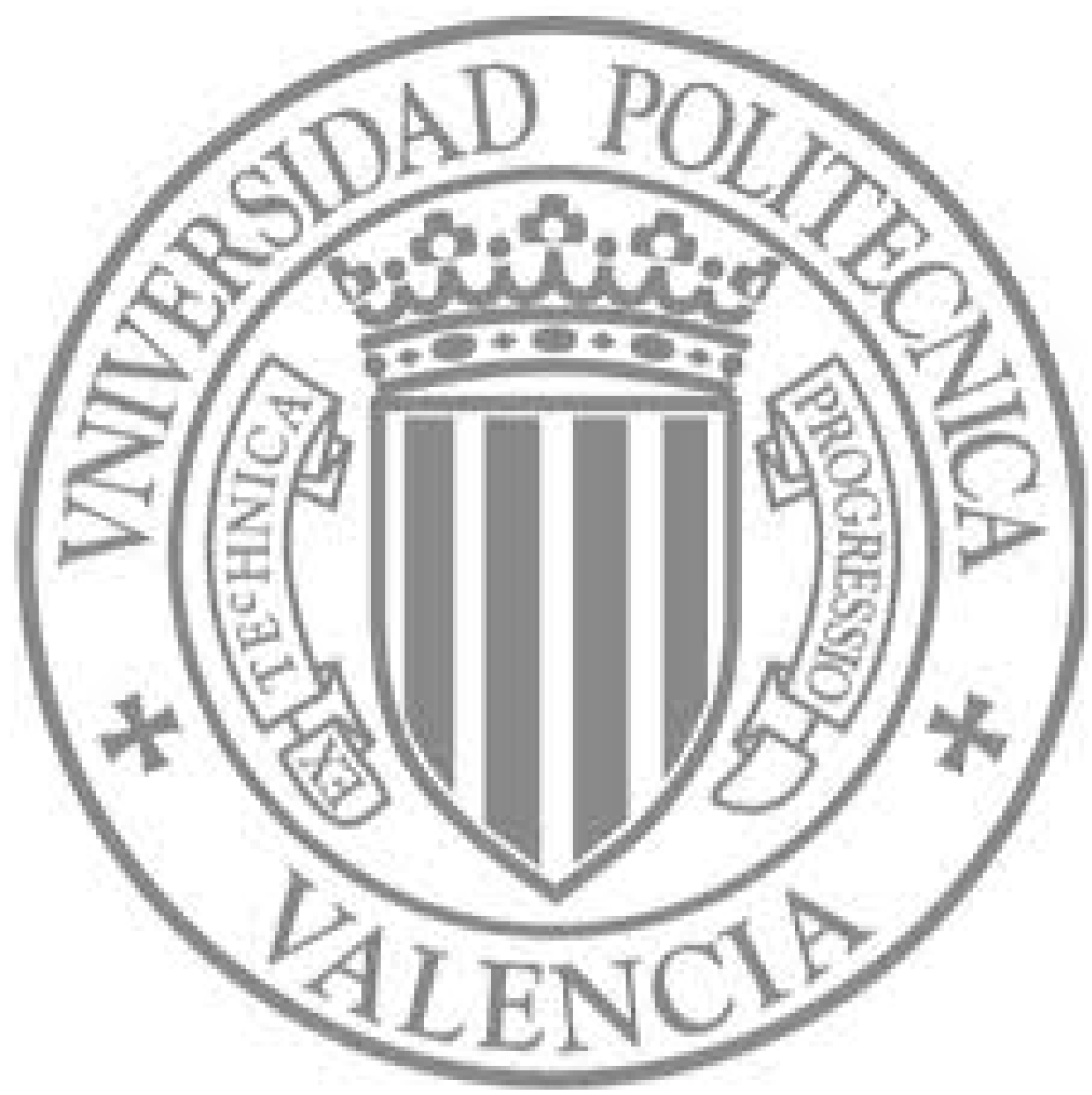

The final publication is available at

http://dx.doi.org/10.1016/j.enconman.2010.10.018

Copyright Elsevier 


\title{
METHODOLOGY FOR VALIDATING TECHNICAL TOOLS TO ASSESS CUSTOMER DEMAND RESPONSE. APPLICATION TO A COMERCIAL CUSTOMER
}

\author{
Manuel Alcázar Ortega, Guillermo Escrivá Escrivá ( $\left.{ }^{*}\right)$, Isidoro Segura Heras \\ Institute for Energy Engineering, Universidad Politécnica de Valencia, \\ Camino de Vera, s/n, edificio 8E, escalera F, $5^{\text {a }}$ planta. 46022 Valencia (SPAIN)
}

\begin{abstract}
The authors present a methodology, which is demonstrated with some applications to the commercial sector, in order to validate a Demand Response (DR) evaluation method previously developed and applied to a wide range of industrial and commercial segments, whose flexibility was evaluated by modeling. DR is playing a more and more important role in the framework of electricity systems management for the effective integration of other Distributed Energy Resources. Consequently, customers must identify what they are using the energy for in order to use their flexible loads for management purposes. Modeling tools are used to predict the impact of flexibility on the behavior of customers, but this result needs to be validated since both customers and grid operators have to be confident in these flexibility predictions. An easy-touse two-steps method to achieve this goal is presented in this paper.
\end{abstract}

Keywords: Deregulated power markets; Distributed energy resources; Demand response resources; Demand modeling; Responsive demand participation

(*) Corresponding author: Tel. +34 963879 240; Fax: +34 963877 272. E-mail address: guieses@die.upv.es 


\section{Nomenclature}

$\sigma_{i}^{\text {Ss }}$, Coefficient of shape for the static simulation

$\sigma^{\mathrm{Cs}}$, Coefficient of consumption for the static simulation

$\sigma_{i}^{\text {Sd }}$, coefficient of shape for the dynamic simulation

$\sigma^{\mathrm{Cd}}$, Coefficient of consumption for the dynamic simulation

$\mathrm{C}_{\text {int }}$, Consumption reduced during the flexibility action, in $\mathrm{kWh}$

$\mathrm{C}_{\text {rec }}$, Consumption during the next time after finishing the flexibility action (recovering

period effect), in $\mathrm{kWh}$

t, Starting time for the flexibility action, in hours

$\mathrm{h}$, Duration of the flexibility action, in hours

$\mathrm{P}_{\mathrm{i}}^{\top}$, Mean power demanded during the hour $i$, in $\mathrm{kW}$

$\mathrm{P}_{i}^{\mathrm{S}}$, Mean power simulated for the hour $i$ without implementation of flexibility, in kW

$\mathrm{P}_{\mathrm{i}}^{\mathrm{FS}}$, Mean hourly power simulated for the hour with implementation of flexibility $i$, in kW

\section{Introduction}

As a consequence of the gradual increasing of electricity demand produced during the last years, together with the massive implementation of renewable resources, different studies about the expected growth of electricity consumption in Europe were developed in the last years. Some of them indicated values at a rate of about $1.4 \%$ per year [1]. It was more critical in the case of some countries such as Spain, where the demand of electricity experienced a growth of $4.0 \%$ in 2006 and $4.2 \%$ in 2007 with respect to the previous year, after discounting the influence of labor and temperature [2]. Although electricity demand has decreased in 2009 due to the special situation that the global economy is suffering nowadays, the implementation of new renewable resources of generation, especially wind power, has shot up [3]. It means a notable increment in the variability and unpredictability of the generation and the consequently more expensive management of the grid, which increases the probability of contingencies which require reductions in demand to avoid blackouts.

One mechanism to reduce demand selectively is by paying end users to become partly or completely interruptible [4]. The planning, implementation and monitoring of utility activities 
designed to encourage consumers to modify patterns of electricity usage is known as Demand Side Management (DSM) [5]. DSM has been commonly used in the operation of electricity systems for years [6]. Nevertheless, only DSM programs for large industrial customers were used to being developed. For practical reasons small and residential consumers were usually not allowed to participate directly in markets; however, they could participate by aggregators in a similar way.

Since the year 2000, both in the USA [7, 8] and Europe, [9] new research has been done in order to develop new DSM programs which have been able to involve commercial and residential customers in the operation of the electricity systems. For the case of Europe, the commercial sector was analyzed in detail in the EU-DEEP project [9], where utilities covering more than 80 million customers all over Europe have been involved.

As a part of that project, a new methodology was developed $[10,11]$ in order to identify the most promising segments [12] according to their flexibility potential, as well as a powerful modeling tool which is able to determine the amount of flexible power that can be reduced by a customer or a group of customers. Since the previously available models were not valid for modeling situations in which the load demand does not follow the usual or stationary patterns, this new modeling tool tries to fill a gap between the existing ones, where the need of more suitable models to evaluate flexibility purposes (load control actions, insert of technologies that modify the traditional way these loads react, etc.) arises.

Similarly, the analysis of different validation methodologies for modeling purposes [13-15] existing in the bibliography, showed the necessity to develop a new methodology to validate these results, since they are not based in dynamic but in static parameters and they do not fit with our purposes about flexibility issues. The proposed methodology is illustrated through its application to a large offices building in the UK, which was studied in the EU-DEEP project.

\section{Validation Methodology}

The methodology which has been developed for validation purposes is divided into two steps, as shown in the flowchart of Figure 1. 


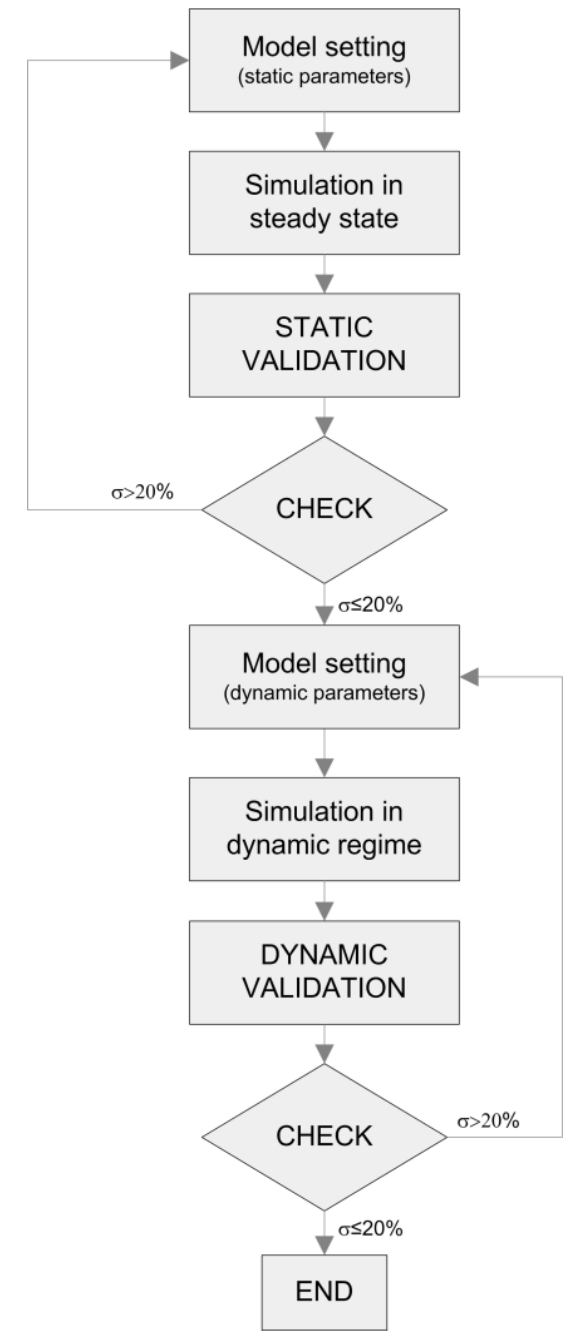

Figure 1. Validation methodology flowchart

As commented above, simulations are performed by using the software developed by UPV in the framework of EU-DEEP project. This tool is based on Matlab® and offers the electricity load profile for a whole day, according to the temperature and environmental conditions for this day.

This is a physically based modeling tool, therefore a previous task of gathering detailed information about the site to be modeled is required. Availability of this information when it comes the time to validate the methodology is as important as properly defining the physical conditions around the location of the site, since this data may be required in order to make the necessary changes and adjustments in the model.

Physical parameters to build the model can be divided into the following items:

- Geographical parameters: Altitude over the sea level and latitude of the site. 
- Constructive parameters: Composition of internal and external walls, including type of materials and thickness; orientation of walls; type and distribution of windows.

- Cooling/Heating: Coefficient of performance of devices involved in cooling and heating in the site; nominal and stand-by power; thermostat adjustment tolerances.

- Weather parameters: Daily profile of external temperature for the day to be simulated; thermostat set point values; initial temperature in adjacent rooms.

- Thermal charges: Ventilation, occupancy, lighting, electronic devices.

The most significant groups of parameters to play with in order to adjust the model will be constructive and weather parameters. Constructive parameters are going to determine the thermal inertia of the system, therefore losses due to the isolation level could be adjusted in order to fit real and simulated load curve.

The influence of the atmospheric conditions is crucial to get a good simulation, so it is important to have a proper set of temperature measurements. Weather parameters will also be used when flexibility actions have to be carried out by the modification of the set point thermostat value.

Bellow the two steps are presented into which the methodology has been divided. First of all, the validation of the model by working in steady state is necessary in order to adjust the real load curve with the simulation (static validation). The second step (dynamic validation) is the comparison between the simulated flexibility and the results from the real test performing, after that the model will be completely validated.

\subsection{Step 1: Static Validation}

The first step for validation purposes resides in the comparison between the real load curve and the simulation obtained with the model. As the first action, the model setting has to be done by putting in the model all the information regarding the initial status of the site whose study is going to be performed.

Once the model has been set, the simulation is run and the initial load curve is obtained. Validation 1 is then done taking into account two aspects: 
- Condition 1 - Shape criteria: Load shape fitting is checked by comparing the difference between both simulated and real load curves before the flexibility action, since the recovery period could affect the shape of the curve after reducing the load. This is why the following has to be confirmed:

$\forall i \in[1, t] \quad \sigma_{i}^{S s}=\frac{P_{i}^{T}-P_{i}^{S}}{P_{i}^{T}} \leq 20 \%$

where $i$ represents each hour for the considered day from 0:00 to the hour $t$

- Condition 2 - Consumption criteria: Coherence between both real and simulated daily energy consumption needs to be verified. This is why the following has to be confirmed:

$$
\sigma^{C s}=\frac{\left(\sum_{i=1}^{24} P_{i}^{T}-C_{r e c}+(h+1) \cdot C_{\mathrm{int}}\right)-\sum_{i=1}^{24} P_{i}^{S}}{\left(\sum_{i=1}^{24} P_{i}^{T}-C_{r e c}+(h+1) \cdot C_{\mathrm{int}}\right)} \leq 20 \%
$$

where $i$ represents each hour for the considered day and it takes values from 1 to 24 $\mathrm{C}_{\text {int }}$ is used to allow the energy consumption from a real test to be compared with energy consumption values obtained from the simulation, since daily energy consumption in real test is reduced due to the performance of a flexibility action. $C_{\text {int }}$ is calculated by using the following expression:

$$
C_{\mathrm{int}}=\frac{\sum_{i=(t-2)}^{t} P_{i}^{T}+\sum_{i=(t+h+1)}^{t+h+3} P_{i}^{T}}{4} \quad i \in[1,24]
$$

In order to discount the effect of a recovering period after the flexibility action in obtaining the energy consumption in steady state, the energy consumptions during the following hour to the last time in which the usual energy profile has been modified $\left(\mathrm{C}_{\text {red }}\right)$ will be substituted by the amount estimated by the factor $C_{\text {int. }}$. This effect has been considered by the term $h+1$ in (2).

This is an easy-to-use method which could be very useful when no more historical data are available. Nevertheless, it is important to point out that its validity is limited to values of $h$ between 1 and 2 hours, which are besides, the usual ones for flexibility actions when thermal 
loads are used for this purpose in the short time, as comfort levels admitted by the customer may be affected by longer actions. For longer actions, there is a sort of more complex methods [16] based on historical data in order to obtain the baseline to compare with the model. If both conditions 1 and 2 are satisfied, then the first step of the validation is fulfilled.

\subsection{Step 2: Dynamic Validation}

The second step in this methodology is based on the comparison between the theoretical flexibility obtained in simulations and results from the real test in which this action has been actually effected.

First of all, parameters related to flexibility have to be set in the model in order to get the amount of energy reduced as a result of the selected flexibility action, as well as the duration and the amount of power involved in the payback period due to the recovering of the initial status after the energy reduction.

Flexibility actions to be performed are defined by the following characteristics:

- Type of flexibility action: total interruption by switching off devices or partial interruption due to modification in the thermostat set point. The type of flexibility action will determine the amount of power to be reduced.

- Duration of the flexibility action. It is related to the type of flexibility action and the time in advance which is taken to notify the customer about it. A higher amount of reduced power implies a shorter duration. A longer action implies a longer notification in advance.

- Recovery period. It is identified by duration and the fixed amount of power over the baseline in steady state.

The type of action and its duration is defined by the customer. Recovery period characteristics, as well as the amount of reduced power if a thermostat variation is the selected option to be simulated, are obtained as a result of the simulation.

Similarly to step 1 , shape and consumption aspects have to be considered as indicated below:

- $\quad$ Condition 1 - Shape criteria: Load shape fitting is checked by comparing the difference between both simulated and real load curves after the flexibility 
action for the whole day in that (in which)the action has taken place. It has to be confirmed that:

$\forall i \in[1,24] \quad \sigma_{i}^{S d}=\frac{P_{i}^{T}-P_{i}^{F S}}{P_{i}^{T}} \leq 20 \%$

where $i$ represents each hour for the considered day and it takes values from 1 to 24

- $\quad$ Condition 2 - Consumption criteria: It will be verified by the coherence between both real and simulated daily energy consumption. It has to be confirmed that:

$\sigma^{C d}=\frac{\sum_{i=1}^{24} P_{i}^{T}-\sum_{i=1}^{24} P_{i}^{F S}}{\sum_{i=1}^{24} P_{i}^{T}} \leq 20 \%$

where $i$ represents each hour for the considered day and it takes values from 1 to 24

If any of these conditions is not true, an adjustment of the model parameters will be required. When both conditions 1 and 2 are satisfied, then the model can be regarded as validated for the studied flexibility action.

\section{Application to a commercial customer}

Proposed methodology has been applied in the framework of the EU-DEEP project, as commented previously, in order to validate the estimated flexibility for a wide range of industrial and commercial segments. As practical example, the case of the commercial segment is presented here, "Large Offices" in the north of Europe. A real consumer from UK has been selected as the typical customer to represent this segment. The following are its main characteristics:

- NACE: 99.01

- Segment Code: 99.01-04 - Large offices - North of Europe

- Electricity consumption: $0.16<$ annual consumption $<1.25 \mathrm{GWh}$

- Gas consumption: annual consumption < $116 \mathrm{GWh}$ 
The flexibility action to be implemented is an increment in the thermostat set point from $23^{\circ} \mathrm{C}$ to $25^{\circ} \mathrm{C}$ for 1 hour in the afternoon (from 14:00 to $15: 00$ hours). The measured load curve for the air conditioning end use is shown in Figure 2. The test was carried out on July 31st 2008.

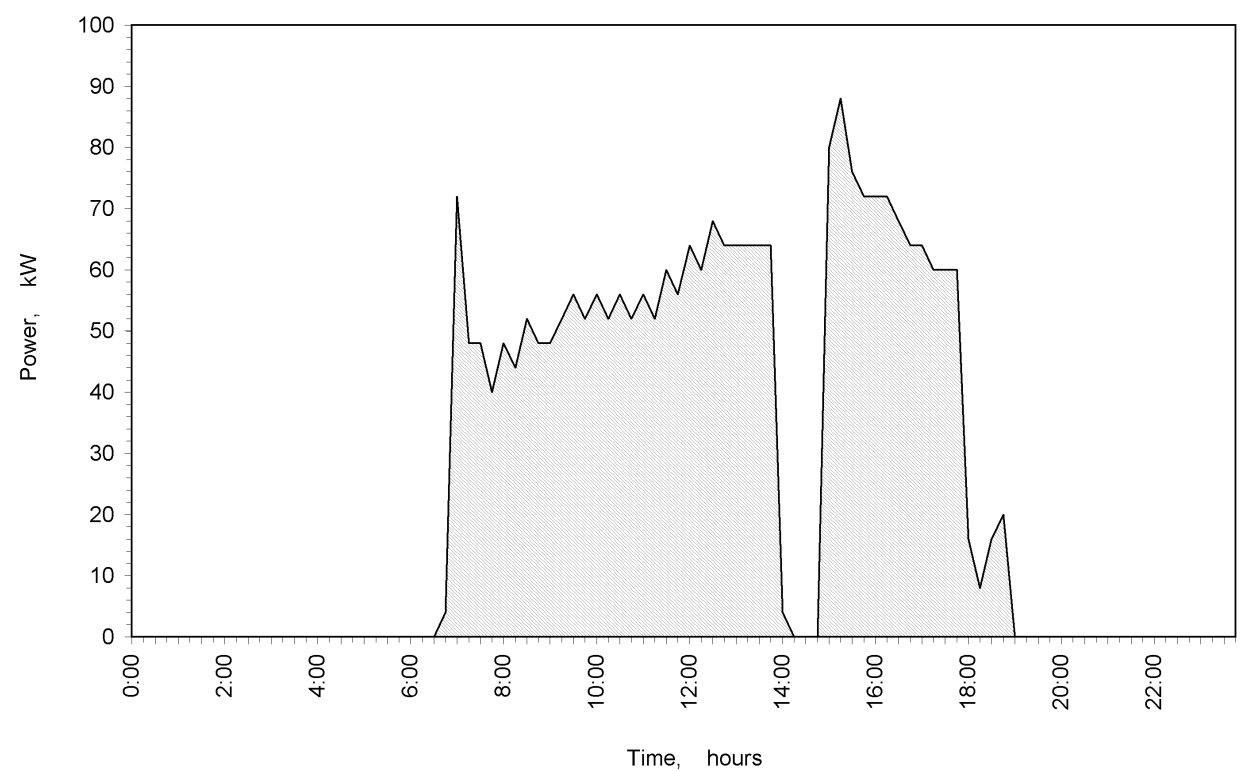

Figure 2. Measured air conditioning load curve from the real test performed in a large offices building. The thermostat set point was increased in two degrees from 14:00 to 15:00 hours.

A first simulation without flexibility was done in steady state in order to apply the first step of the validation methodology. Figure 3 shows the final load curve obtained with the modeling tool after several iterations in order to adjust the model, as well as the load curve from the test. 


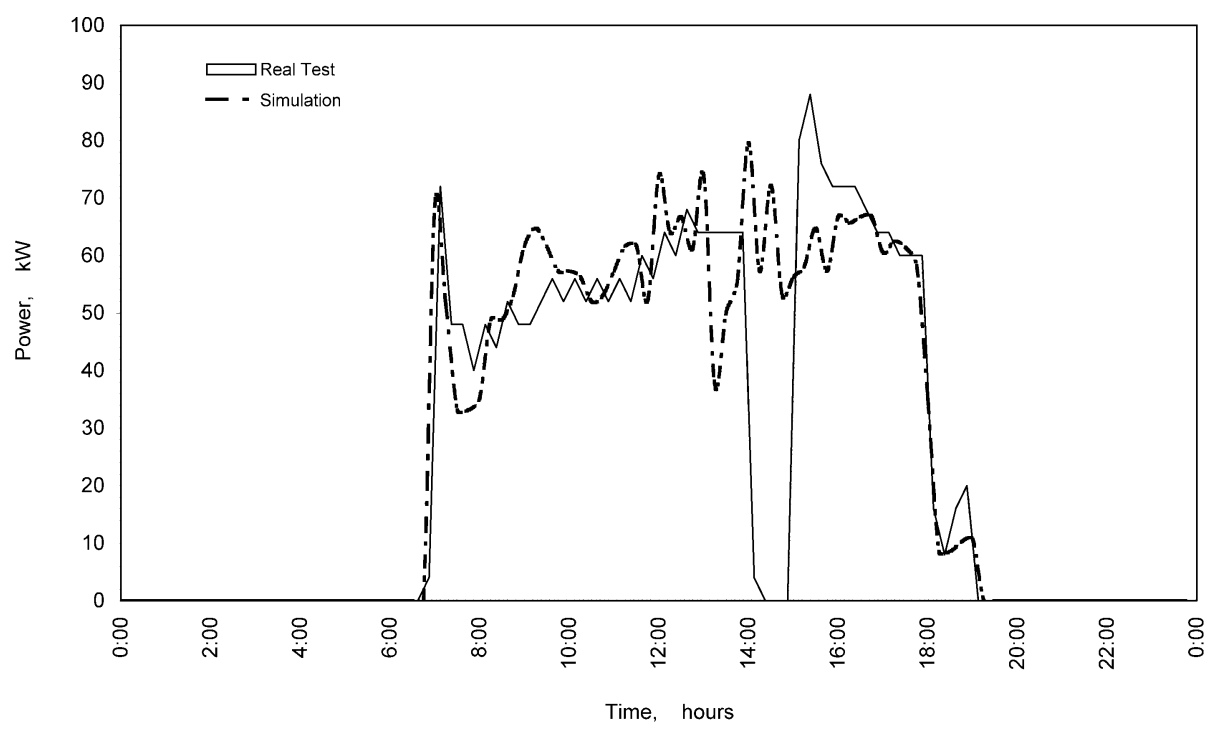

Figure 3. Real and modeled load curves for a large offices building in the north of Europe.

Stationary behavior was considered for modeling purposes, therefore reduction in power demand in the afternoon is not included in the simulated curve.

Table 1 includes the coefficients $\sigma_{i}^{\text {Ss }}$ for each hour before the interruption, calculated with (1). According to the obtained values, all the coefficients agree with the static validation requirements.

Table 1. Values for $\sigma_{1}^{\text {ss }}$

\begin{tabular}{rr}
\multicolumn{1}{r}{} & \multicolumn{1}{c}{$\boldsymbol{\sigma}_{\mathbf{i}}^{\mathbf{s s}}$} \\
\hline 1 & $0.0 \%$ \\
2 & $0.0 \%$ \\
3 & $0.0 \%$ \\
4 & $0.0 \%$ \\
5 & $0.0 \%$ \\
6 & $0.0 \%$ \\
7 & $0.0 \%$ \\
8 & $10.4 \%$ \\
9 & $3.2 \%$ \\
10 & $17.9 \%$ \\
11 & $1.2 \%$ \\
12 & $3.9 \%$ \\
13 & $3.8 \%$ \\
14 & $15.2 \%$ \\
15 & - \\
16 & - \\
17 & - \\
18 & - \\
19 & - \\
20 & - \\
21 & - \\
22 & - \\
23 & - \\
24 & -
\end{tabular}


Regarding to the coefficient $\sigma^{\mathrm{Cs}}$, it takes the value $0.92 \%$ by using (2), so static validation was performed successfully.

For dynamic validation, the model parameters were set according to the real test conditions, and the simulation of the flexibility -as explained at the beginning of this section -was done. Figure 4 shows the modeled load curve when the flexibility action is compared to the real test curve:

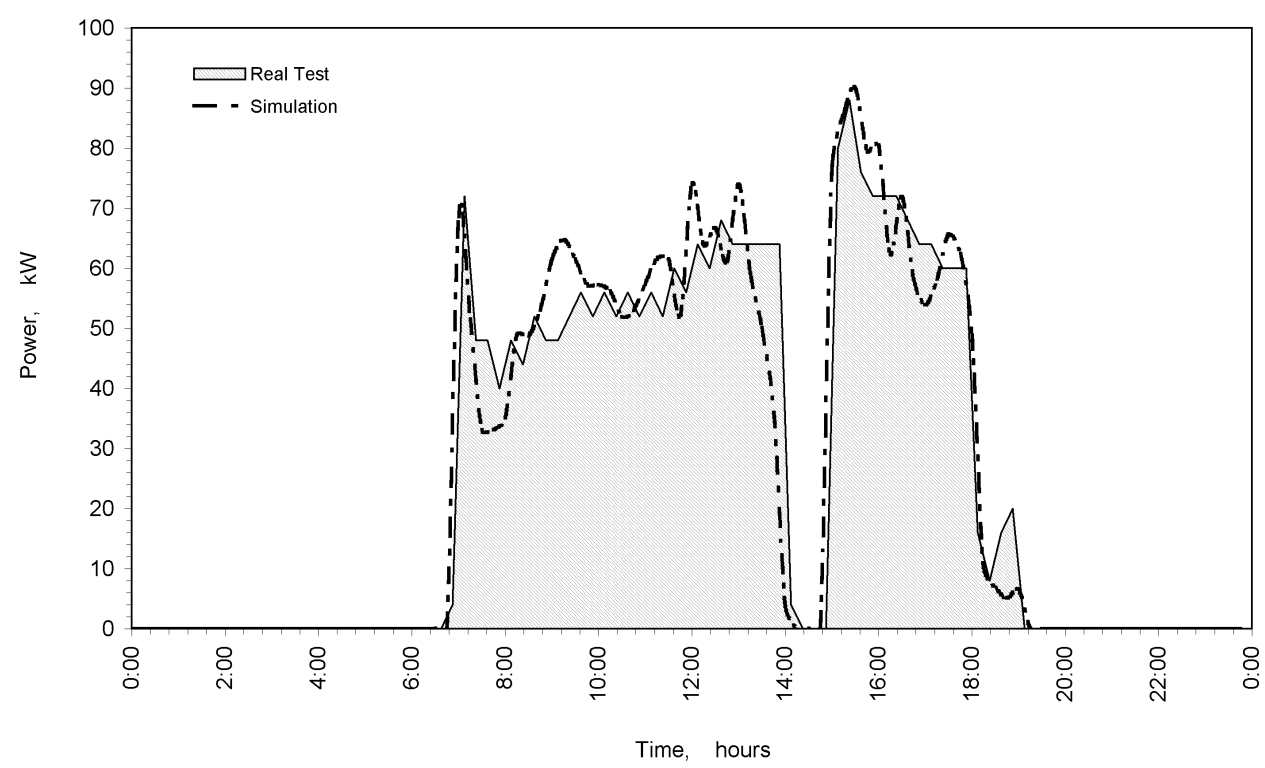

Figure 4. Real and modeled load curves for a large offices building in the north of Europe.

Thermostat set point was increased to $2^{\circ} \mathrm{C}$ from $14: 00$ to $15: 00$ hours.

Table 2 includes the coefficients $\sigma_{i}^{\text {sd }}$ for each hour, calculated with (4). Similarly to the static validation, all the coefficients agree with the dynamic validation requirements. 
Table 2. Values for $\sigma_{i}^{\text {Sd }}$

\begin{tabular}{rr}
$\mathbf{i}$ & \multicolumn{1}{c}{$\boldsymbol{\sigma}_{\mathbf{i}}^{\mathbf{S d}}$} \\
\hline 1 & $0.0 \%$ \\
2 & $0.0 \%$ \\
3 & $0.0 \%$ \\
4 & $0.0 \%$ \\
5 & $0.0 \%$ \\
6 & $0.0 \%$ \\
7 & $0.0 \%$ \\
8 & $10.4 \%$ \\
9 & $3.2 \%$ \\
10 & $17.9 \%$ \\
11 & $1.2 \%$ \\
12 & $3.9 \%$ \\
13 & $3.8 \%$ \\
14 & $14.3 \%$ \\
15 & $4.8 \%$ \\
16 & $5.1 \%$ \\
17 & $1.0 \%$ \\
18 & $1.5 \%$ \\
19 & $18.5 \%$ \\
20 & $0.0 \%$ \\
21 & $0.0 \%$ \\
22 & $0.0 \%$ \\
23 & $0.0 \%$ \\
24 & $0.0 \%$
\end{tabular}

Coefficient $\sigma^{\mathrm{Cs}}$ takes in this case the value $0.84 \%$ by using (5), so dynamic validation was also performed successfully.

Once both static and dynamic validations have been satisfactorily evaluated, the model could be considered as calibrated and verified to estimate the effect of the implementation of similar flexibility actions. The participation in a sort of new DR programs of other commercial customers, like the one evaluated in this example, is currently being explored, where the flexibility estimated and validated by means of this methodology plays an essential role.

\section{Conclusions}

This paper presents a two-step methodology designed to validate the flexibility of a wide range of commercial and industrial segments which has been previously calculated by using a modeling tool developed by the authors. The first step (static validation) lies in the verification of correspondence between the usual load curve of a customer obtained by simulation (without flexibility) and the real load curve of the customer. The effect of applying flexibility is completely validated in a second step (dynamic flexibility) where the simulated flexibility is verified through 
a real test. Some coefficients have been proposed in order to systematize this calculation. Once the model has been calibrated and validated, the effect of similar demand side management options could be evaluated, as no measurement campaigns may exist about the strategies to be simulated.

A real example of the application of this methodology to the commercial segment has been described, as well as the obtained results, which allows the customer to validate the predictions made by the modeling tool regarding its flexibility. It results to a reliable estimation of the effect of flexibility actions applied to the customer's facility, which would help the customer to know how to use this flexibility in electricity operation markets in a profitable way.

\section{Acknowledgments}

The authors gratefully acknowledge the contributions of EU-DEEP project participants. This work was supported in part by the European Commission within the Sixth Framework Programme for Research and Technological Development.

\section{References}

[1] Farinelli, U., Gusmerotti, M. Evaluation of the Long-Term Evolution of Electricity Demand in the European Union. 26th USAEE/IAEE North American Conference, Ann Arbor, pp. 24-27, September 2006

[2] Red Eléctrica de España. Annual Report 2007, pp. 18. Available on http://www.ree.es accessed in January 2009

[3] Red Eléctrica de España. Annual Report 2009 (advance), pp. 7. Available on http://www.ree.es accessed in January 2010

[4] Energy Systems Integration - Demand Response. The California Energy Commission. http://www.energy.ca.gov accessed in January 2009

[5] Energy Information Administration Glossary. Official Energy Statistics from the U.S.

Government. http://www.eia.doe.gov accessed in January 2009

[6] Mickle C. Energy Services and DSM in the Competitive Energy Supply Market. IEE, Savoy Place, London, pp. 3, 1994 
[7] CAISO Demand Response Resource User Guide - Guide to Participation in Market Redesign and Technology Upgrade (MRTU). The California Independent System Operator. Available on http://www.caiso.com/1893/1893e350393b0.html, November 29, 2007 [8] International Energy Agency (IEA) Demand Response Resources - Task XIII. Available on http://demandresponseresources.com accessed in January 2010

[9] The birth of a EUropean Distributed EnErgy Energy Partnership that will help the large-scale implementation of distributed energy resources in Europe (EU-DEEP), the European Project supported by the Sixth Framework programme for Research and Technological Development. http://www.eu-deep.com accessed in January 2010

[10] Álvarez, C., Alcázar, M., Escrivá., G, Gabaldón, A. "Technical and economical tools to assess customer demand response in the commercial sector". Energy Conversion and Management, No. 50, pp. 2605-2612, 2009

[11] Álvarez, C., Gabaldón, A., and Molina, A. Assessment and Simulation of the Responsive Demand Potential in End-User Facilities: Application to a University Customer. IEEE Trans. Power Syst., No. 19, (2), pp. 1223-1231, 2004

[12] Afonso, D., Pérez-Navarro, A., Encina, N., Álvarez, C., Rodríguez, J. and Alcázar, M. A methodology for ranking of customer segments by their suitability for Distributed Energy Resources applications. Energy Conversion and Management, No. 48, pp. 1615-1623, 2007 [13] Widén, J. and Wäckelgård, E. A high-resolution stochastic model of domestic activity patterns and electricity demand". Applied Energy, doi: 10.1016/j.apenergy.2009.11.006, 2009 [14] Truong, N.,Wang, L.,Wong, P. Modelling and short-term forecasting of daily peak power demand in Victoria using two-dimensional wavelet based SDP models. Electrical Power and Energy Systems, No. 30, pp. 511-518, 2008

[15] Göransson L. and Johnsson, F. Dispatch modeling of a regional power generation system Integrating wind power. Renewable Energy, No. 34, pp. 1040-1049, 2009

[16] Encinas, N., Domijan A., Álvarez C., Rodríguez J., Masiello, J.A. Settlement Computation in Demand Response Programs: Comparing Baseline Methods. Proceedings of the Seventh IASTED International Conference on Power and Energy Systems, Clearwater (Florida), 2004 